\title{
HUBUNGAN TINGKAT PENGETAHUAN DAN SIKAP IBU HAMIL TERHADAP PERILAKU PENCEGAHAN TOKSOPLASMOSIS DI WILAYAH KERJA PUSKESMAS BLAHBATUH I TAHUN 2017
}

\author{
Ni Made Oka Anggreni*, Desak Putu Yuli Kurniati, I Made Subrata \\ Program Studi Kesehatan Masyarakat Fakultas Kedokteran Universitas Udayana \\ ${ }^{*}$ E-mail: renny868@yahoo.com
}

\begin{abstract}
ABSTRAK
Seroprevalensi toksoplasmosis pada wanita di Bali tahun 2013 sebesar 63,9\% dan seroprevalensi tertinggi wanita terinfeksi T. gondii berada di Kabupaten Gianyar sebesar 82,5\%. Pada tahun 2016 Puskesmas Blahbatuh I memiliki kasus abortus yang paling tinggi di antara 13 Puskesmas yang ada di Kabupaten Gianyar yaitu sekitar 15,58\%. Tujuan dari penelitian ini adalah untuk mengetahui hubungan tingkat pengetahuan dan sikap ibu hamil terhadap perilaku pencegahan toksoplasmosis di wilayah kerja Puskesmas Blahbatuh I tahun 2017. Jenis penelitian yang digunakan adalah cross sectional analitik. Sampel 75 ibu hamil yang dipilih dengan teknik probability sampling. Pengumpulan data meliputi pengetahuan, sikap, dan perilaku pencegahan menggunakan kuesioner dan dianalisis dengan menggunakan program komputer. Hasil penelitian menunjukkan bahwa sebanyak 20,0\% responden memiliki perilaku pencegahan kurang, 52,0\% responden memiliki pengetahuan kurang, dan 37,3\% responden memiliki sikap kurang. Tidak terdapat hubungan yang signifikan antara tingkat pengetahuan terhadap perilaku pencegahan dengan nilai $P R=2,167$, dan terdapat hubungan yang signifikan antara sikap terhadap perilaku pencegahan dengan nilai PR=8,34. Jadi, di wilayah kerja Puskesmas Blahbatuh I dari 75 ibu hamil memiliki tingkat pengetahuan kurang, sikap kurang, dan perilaku pencegahan kurang. Tidak terdapat hubungan yang signifikan antara tingkat pengetahuan terhadap perilaku pencegahan dan terdapat hubungan yang siginfikan antara sikap terhadap perilaku pencegahan. Oleh karena itu Puskesmas Blahbatuh I harus meningkatkan pengetahuan dan sikap ibu hamil tentang toksoplasmosis dengan cara memberikan KIE pada saat pemeriksaan antenatal agar ibu hamil dapat melakukan pencegahan dengan baik.
\end{abstract}

Kata kunci: Kehamilan, Toksoplasmosis, Pengetahuan, Sikap, Perilaku Pencegahan

\section{ABSTRACT}

Toxoplasmosis seroprevalence of women in Bali in 2013 was $63.9 \%$ and the highest seroprevalence of women infected with T. gondii was in Gianyar Regency by 82.5\%. In 2016 Blahbatuh I Public Health Center had the highest abortion cases among 13 Community Health Centers in Gianyar Regency, which was around 15.58\%. The purpose of this study was to determine the relationship of the level of knowledge and attitudes of pregnant women to the prevention of toxoplasmosis in the work area of Blahbatuh I Public Health Center in 2017. The type of research used was cross sectional analytic. Sample 75 pregnant women selected with probability sampling technique. Data collection includes knowledge, attitudes, and preventative behavior using a questionnaire and analyzed using a computer program. The results showed that as many as $20.0 \%$ of respondents had less preventive behavior, $52.0 \%$ of respondents had less knowledge, and $37.3 \%$ of respondents had less attitude. There is no significant relationship between the level of knowledge of preventive behavior with a PR value $=2.167$, and there is a significant relationship between attitudes towards preventive behavior with a PR value of 8.34 . So, in the working area of Blahbatuh I Public Health Center out of 75 pregnant women have less knowledge, less attitudes, and less preventive behavior. There is no significant relationship between the level of knowledge of preventive behavior and there is a significant relationship between attitudes towards preventive behavior. Therefore Puskesmas Blahbatuh I must improve the knowledge and attitudes of pregnant women about toxoplasmosis by providing IEC during antenatal examinations so that pregnant women can take preventative measures properly.

Keywords: Pregnancy, Toxoplasmosis, Knowledge, Attitude, Preventive Behavior

\section{PENDAHULUAN}

Kehamilan merupakan suatu proses fisiologik yang hampir selalu terjadi pada setiap wanita. Tetapi tidak semua setiap wanita mengalami kehamilan secara normal. Banyak penyakit infeksi yang menyertai 
kehamilan diantaranya, Hipertensi, Anemia, Hepatitis, ISK (Infeksi Saluran Kencing), HIV/AIDS, Tifus Abdominalis, dan Toksoplasmosis. Toksoplasmosis merupakan salah satu penyakit berbahaya yang harus diwaspadai saat kehamilan pada umumnya (Abidin, 2014). Di Indonesia kasus toksoplasmosis berkisar antara 43 kasus (88\%).

Di Bali pada tahun 2013 seroprevalensi toksoplasmosis pada wanita di Bali sebesar $63,9 \%$, dan seroprevalensi tertinggi wanita terinfeksi T. gondii berada di Kabupaten Gianyar sebesar 82,5\% (Laksemi, et. al., 2013). Pada tahun 2016 Puskesmas Blahbatuh I memiliki kasus abortus yang paling tinggi diantara 13 Puskesmas yang ada di Kabupaten Gianyar yaitu sekitar 15,58\% (Dinkes Kabupaten Gianyar, 2016).

Manusia dan hewan termasuk unggas dapat menderita toksoplasmosis. Penularan toksoplasmosis dapat masuk ke dalam tubuh manusia dalam berbagai cara. Pertama, secara tidak sengaja menelan tinja kucing yang di dalamnya terdapat telur toksoplasmosis. Cara ini banyak tidak disadari, misalnya menyentuh mulut dengan tangan yang telah terkontaminasi seperti sehabis berkebun, membersihkan tempat makan kucing atau barang-barang lain yang sudah terkontaminasi. Kedua, parasit ini juga dapat masuk jika mengkonsumsi daging hewan yang telah terkontaminasi dan tidak dimasak secara matang. Bentuk kista dari parasit ini dapat masuk bersama daging hewan tadi. Ketiga, masuk lewat air yang telah terkontaminasi (Chahaya, 2003).

Banyak faktor yang menjadi penyebab tingginya angka kejadian abortus di wilayah kerja Puskesmas Blahbatuh I, salah satu faktor yang dapat mempengaruhi adalah tingkat pengetahuan dan sikap ibu hamil terhadap toksoplasmosis. Hal tersebut disebabkan karena di wilayah kerja Puskesmas Blahbatuh I belum adanya program spesifik toksoplasmosis di tingkat puskesmas yang merupakan masalah lain dari cukup tingginya infeksi toksoplasmosis di wilayah kerja Puskesmas Blahbatuh I. Hasil penelitian yang dilakukan oleh Widiani (2016) di wilayah kerja Puskesmas Blahbatuh I diperoleh data bahwa sebagian besar $87,32 \%$ responden beresiko untuk terinfeksi T. gondii. Pengetahuan dan sikap merupakan domain dari perilaku (Notoatmodjo, 2007), oleh karena itu peneliti ingin melakukan penelitian kuantitatif mengenai hubungan tingkat pengetahuan dan sikap ibu hamil terhadap perilaku pencegahan toksoplasmosis di wilayah kerja Puskesmas Blahbatuh I.

\section{METODE PENELITIAN}

Jenis penelitian yang digunakan adalah cross sectional analitik. Penelitian ini dilakukan di wilayah kerja Puskesmas Blahbatuh I, karena penelitian tentang hubungan tingkat pengetahuan dan sikap ibu hamil terhadap perilaku pencegahan toksoplasmosis belum pernah dilakukan di tempat ini. Waktu penelitian ini dimulai pada bulan April-Mei 2017. Sampel yang diteliti pada penelitian ini adalah 75 ibu hamil yang ada di wilayah kerja Puskesmas Blahbatuh I. Dalam penelitian ini teknik pengambilan sampel dilakukan dengan teknik probability sampling dengan simple random sampling. Di wilayah kerja Puskesmas Blahbatuh I terdapat lima puskesmas pembantu, maka penentuan jumlah sampel pada masing-masing puskesmas pembantu menggunakan teknik cluster sampling. Didapatkan pembagian responden pada 
masing-masing wilayah kerja sebagai berikut, 14 responden dari Medahan, 7 responden dari Bona, 20 responden dari Keramas, 2 Responden dari Belega, dan 32 responden dari Pering. Selanjutnya metode pengambilan sampel dapat menggunakan random number, yaitu dengan cara memasukkan semua nomor orang yang termasuk dalam populasi ke dalam sebuah kotak, setelah semuanya terkumpul baru kita ambil 75 orang dari keseluruhan populasi. Pada pengumpulan data digunakan kuesioner yang berisi sederetan pertanyaan tertutup (closed ended question) yang diajukan kepada responden untuk memperoleh informasi dengan skala pengukuran ordinal.

\section{HASIL}

Karakteristik Responden Berdasarkan Umur

Dari keseluruhan responden yaitu 75 ibu hamil yang ada di wilayah kerja Puskesmas Blahbatuh I, rentangan umur responden dimulai dari umur 16-39 tahun.

\section{Karakteristik Responden Berdasarkan Pekerjaan}

Tabel 1 Distribusi Frekuensi Responden Berdasarkan Pekerjaan

\begin{tabular}{lcc}
\hline Karakteristik & Frekuensi & $\begin{array}{c}\text { Persentase } \\
(\mathbf{\%})\end{array}$ \\
\hline IRT & 29 & 38,7 \\
Guru & 2 & 2,7 \\
Pegawai Swasta & 17 & 22,7 \\
Buruh & 3 & 4,0 \\
Wiraswasta & 24 & 31,9 \\
\hline Total & $\mathbf{7 5}$ & $\mathbf{1 0 0 , 0}$ \\
\hline
\end{tabular}

Dari tabel 1 dapat dijelaskan bahwa dari 75 responden yang bekerja sebagai IRT sebanyak 29 responden (38,7\%), Guru sebanyak 2 responden (2,7\%), Pegawai Swasta sebanyak 17 responden $(22,7 \%)$, Buruh sebanyak 3 responden $(4,0 \%)$, dan wiraswasta sebanyak 16 responden $(21,3 \%)$.

\section{Karakteristik Responden Berdasarkan Pendidikan}

Tabel 2 Distribusi Frekuensi Responden Berdasarkan Pendidikan

\begin{tabular}{ccc}
\hline Karakteristik & Frekuensi & $\begin{array}{c}\text { Persentase } \\
\mathbf{( \% )}\end{array}$ \\
\hline SD & 6 & 8,0 \\
SMP & 20 & 26,7 \\
SMA & 39 & 52,0 \\
D1 & 2 & 2,7 \\
S1 & 7 & 9,3 \\
S2 & 1 & 1,3 \\
\hline Total & $\mathbf{7 5}$ & $\mathbf{1 0 0 , 0}$ \\
\hline
\end{tabular}

Tabel 2 menunjukkan hasil karakteristik responden berdasarkan pendidikan, yang terdiri dari pendidikan terakhir SD sebanyak 6 responden $(8,0 \%)$, pendidikan terakhir SMP sebanyak 20 responden $(26,7 \%)$, pendidikan terakhir SMA sebanyak 39 responden (52,0\%), pendidikan terakhir D1 sebanyak 2 responden $(2,7 \%)$, pendidikan terakhir S1 sebanyak 7 responden $(9,3 \%)$, dan pendidikan terakhir S2 sebanyak 1 responden (1,3\%).

\section{Perilaku Pencegahan Ibu Hamil Terhadap Toksoplasmosis}

Perilaku pencegahan toksoplasmosis ibu hamil dibagi menjadi perilaku pencegahan baik dan kurang.

Tabel 3 Distribusi Frekuensi Perilaku Pencegahan Toksoplasmosis Pada Ibu Hamil

\begin{tabular}{lcc}
\hline $\begin{array}{c}\text { Perilaku } \\
\text { Pencegahan }\end{array}$ & Frekuensi & $\begin{array}{c}\text { Persentase } \\
\mathbf{( \% ) ~}\end{array}$ \\
\hline Baik & 15 & 20,0 \\
Kurang & 60 & 80,0 \\
\hline Total & $\mathbf{7 5}$ & $\mathbf{1 0 0}$ \\
\hline
\end{tabular}


Tabel di atas menunjukkan bahwa perilaku ibu hamil terhadap pencegahan toksoplasmosis dengan kategori baik yaitu sebanyak 15 responden (20,0\%), dan kurang yaitu sebanyak 60 responden $(80,0 \%)$.

\section{Tingkat Pengetahuan Ibu Hamil Terhadap Toksoplasmosis}

Tingkat pengetahuan ibu hamil tentang toksoplasmosis dibagi menjadi dua kategori yaitu tingkat pengetahuan baik dan kurang.

Tabel 4 Distribusi Frekuensi Tingkat Pengetahuan Ibu Hamil Terhadap Toksoplasmosis

\begin{tabular}{ccc}
\hline Pengetahuan & Frekuensi & $\begin{array}{c}\text { Persentase } \\
\text { (\%) }\end{array}$ \\
\hline Baik & 36 & 48,0 \\
Kurang & 39 & 52,0 \\
\hline Total & $\mathbf{7 5}$ & $\mathbf{1 0 0}$ \\
\hline
\end{tabular}

Pada tabel di atas menunjukkan bahwa tingkat pengetahuan ibu hamil tentang toksoplasmosis dengan kategori baik yaitu sebanyak 36 responden $(48,0 \%)$ dan kategori kurang yaitu sebanyak 39 responden $(52,0 \%)$.

\section{Sikap Ibu Hamil Terhadap Toksoplasmosis}

Sikap ibu hamil terhadap toksoplasmosis dibagi menjadi dua kategori yaitu sikap baik dan kurang.

Tabel 5 Distribusi Frekuensi Sikap Ibu Hamil Terhadap Toksoplasmosis

\begin{tabular}{ccc}
\hline Sikap & Frekuensi & $\begin{array}{c}\text { Persentase } \\
(\mathbf{\%})\end{array}$ \\
\hline Baik & 47 & 62,7 \\
Kurang & 28 & 37,3 \\
\hline Total & $\mathbf{7 5}$ & $\mathbf{1 0 0}$ \\
\hline
\end{tabular}

Tabel di atas menunjukkan bahwa sikap ibu hamil terhadap toksoplasmosis dengan kategori baik yaitu sebanyak 47 responden
(62,7\%) dan kategori kurang yaitu sebanyak 28 responden $(37,7 \%)$.

\section{Hubungan Tingkat Pengetahuan Ibu Hamil Terhadap Perilaku Pencegahan Toksoplasmosis}

Berdasarkan hasil analisis dari 75 responden yang memiliki tingkat pengetahuan baik dan perilaku pencegahan baik berjumlah $10(27,8 \%)$ responden, yang memiliki pengetahuan baik dan perilaku pencegahan kurang sebanyak 26 (72,2\%) responden. Selanjutnya responden yang memiliki tingkat pengetahuan kurang dan perilaku pencegahan baik sebanyak $5(12,8 \%)$ responden, yang memiliki tingkat pengetahuan kurang dan perilaku pencegahan kurang sebanyak 34 (87,2\%) responden. Berdasarkan hasil uji analisis hubungan menggunakan chi-square dengan taraf signifikansi $(\alpha=0,05)$ diperoleh hasil bahwa tidak terdapat hubungan yang signifikan antara tingkat pengetahuan dengan perilaku pencegahan toksoplasmosis pada ibu hamil di wilayah kerja Puskesmas Blahbatuh I dengan hasil p-value sebesar 0,106 dan dari hasil analisis didapatkan nilai $P R=2,167$ yang berarti ibu hamil dengan tingkat pengetahuan yang baik memiliki peluang/kesempatan sebesar 2,167 kali lebih besar untuk memiliki perilaku pencegahan baik dibanding dengan ibu hamil yang memiliki tingkat pengetahuan kurang.

\section{Hubungan Sikap Ibu Hamil Dengan Perilaku Pencegahan Toksoplasmosis}

Adapun hasil penelitian yang diperoleh yaitu dari 75 responden yang memiliki sikap baik dan perilaku pencegahan baik sebanyak $14(29,8 \%)$ responden, yang memilki sikap 
baik dan perilaku pencegahan kurang sebanyak $33(70,2 \%)$ responden. Selanjutnya responden yang memiliki sikap kurang dan perilaku pencegahan baik sebanyak 1 (3,6\%) responden, yang memiliki sikap kurang dan perilaku pencegahan kurang sebanyak 27 (96,4\%) responden. Berdasarkan hasil uji analisis hubungan menggunakan chi-square dengan taraf signifikansi $(\alpha=0,05)$ diperoleh hasil bahwa terdapat hubungan yang signifikan antara sikap dengan perilaku pencegahan toksoplasmosis pada ibu hamil di wilayah kerja Puskesmas Blahbatuh I dengan hasil p-value sebesar 0,006 dan dari hasil analisis didapatkan nilai $\mathrm{PR}=8,34$ yang berarti ibu hamil dengan sikap yang baik memiliki peluang/kesempatan sebesar 8,34 kali lebih besar untuk memiliki perilaku pencegahan baik dibanding dengan ibu hamil yang memiliki sikap kurang.

\section{Hubungan Tingkat Pengetahuan dan Sikap Ibu Hamil Terhadap Perilaku Pencegahan Toksoplasmosis}

Untuk mengetahui variabel yang paling dominan dalam mempengaruhi perilaku pencegahan maka perlu dilakukan analisis secara multivariat. Dari hasil analisis multivariat dengan menggunakan metode regresi logistik didapatkan hasil sebagai berikut:

Tabel 6 Tabel Hasil Uji Regresi Logistik Tingkat Pengetahuan dan Sikap Ibu Hamil Terhadap Perilaku Pencegahan Toksoplasmosis.

\begin{tabular}{lccc}
\hline Variabel & $\mathbf{p}$ value & OR & $\mathbf{9 5 \%} \mathbf{~ C l}$ \\
\hline $\begin{array}{l}\text { Tingkat } \\
\text { pengetahuan }\end{array}$ & 0,484 & 1,572 & $0,433-5,580$ \\
Sikap & 0,036 & 9,789 & $1.158-$ \\
& & & 82.722 \\
\hline
\end{tabular}

Dari hasil uji Regresi Logistik didapatkan hasil variabel sikap merupakan variabel dominan yang berhubungan dengan perilaku pencegahan dengan nilai $\mathrm{p}=0,036$. Sedangkan untuk variabel tingkat pengetahuan nilai $p=0,484$. Melihat nilai signifikansi untuk variabel tingkat pengetahuan tersebut berada di atas 0,25 berarti tidak terdapat hubungan yang signifikan antara tingkat pengetahuan dan sikap ibu hamil dengan perilaku pencegahan toksoplasmosis di wilayah kerja Puskesmas Blahbatuh I. Dari hasil analisis statistik dengan menggunakan Regresi Logistik menunjukkan bahwa variabel sikap merupakan variabel dominan yang berhubungan dengan perilaku pencegahan dengan nilai OR sebesar 9,789 yang berarti ibu hamil dengan sikap yang baik memiliki peluang/kesempatan sebesar 9,78 kali lebih besar untuk memiliki perilaku pencegahan baik dibanding dengan ibu hamil yang memiliki sikap kurang.

\section{SIMPULAN}

Berdasarkan hasil penelitian dan pembahasan dapat disimpulkan bahwa ibu hamil di wilayah kerja Puskesmas Blahbatuh I memiliki perilaku pencegahan terhadap toksoplasmosis yang kurang (80,0\%). Ibu hamil di wilayah kerja Puskesmas Blahbatuh I memiliki tingkat pengetahuancd tentang toksoplasmosis yang kurang (52,0\%). Ibu hamil di wilayah kerja Puskesmas Blahbatuh I memiliki sikap terhadap toksoplasmosis yang kurang (37,3\%). Tidak ada hubungan antara tingkat pengetahuan dengan perilaku pencegahan toksoplasmosis dengan nilai $P R=2,167 \quad(p=0,106)$ dan ada hubungan antara sikap dengan perilaku pencegahan toksoplasmosis dengan nilai $\mathrm{PR}=8,34$ $(p=0,006)$. Dari hasil analisis multivariat 
dengan Regresi Logistik menunjukkan bahwa variabel sikap merupakan variabel dominan dengan nilai $\mathrm{OR}=9,789$.

Berdasarkan hasil penelitian ini disarankan kepada Puskesmas Blahbatuh I agar meningkatkan pengetahuan tentang toksoplasmosis dengan cara memberikan KIE pada saat pemeriksaan antenatal agar ibu hamil dapat melakukan pencegahan dengan baik. Bagi peneliti selanjutnya diharapkan untuk melakukan penelitian tentang faktorfaktor lain yang berpengaruh terhadap perilaku pencegahan toksoplasmosis khususnya kepada ibu hamil di wilayah Kerja Puskesmas Blahbatuh I.

\section{DAFTAR PUSTAKA}

Abidin, A. N. (2014). Menghindari dan Mengatasi TORCH. Jakarta: PT. Gramedia.

Chahaya, I. (2003). Epidemiologi Toxoplasma Gondii. Sumatera Utara: Fakultas Kesehatan Masyarakat, Universitas Sumatera Utara.
Dinas Kesehatan Kabupaten Gianyar. (2016). Profil Dinas Kesehatan Kabupaten Gianyar Tahun 2016. Gianyar. Dinas Kesehatan Kabupaten Gianyar.

Laksemi, Sri, D. A. A., Artama, W. T. \& Wijayanti M. A. (2013). Seroprevalensi yang Tinggi dan Faktor - Faktor Risiko Toksoplasmosis pada Darah Donor dan Wanita di Bali. Veteriner. Vol. 14, No. 2, Hal. $204-212$.

Notoatmodjo, P. D. S. (2007). Metodologi Penelitian Kesehatan. Jakarta: Rineka Cipta.

Puskesmas Blahbatuh I. (2016). Profil Kesehatan Puskesmas Blahbatuh I Tahun 2016. Gianyar. Puskesmas Blahbatuh I.

Widiani. (2016). Gambaran Faktor Risiko Toksoplasmosis pada Wanita Hamil di Wilayah Kerja Puskesmas Blahbatuh I Tahun 2016. Program Studi Kesehatan Masyarakat Fakultas Kedokteran Universitas Udayana. 